\title{
A prospective pilot study on MRI visibility of iron oxide-impregnated polyvinylidene fluoride mesh after ventral rectopexy
}

\author{
K. E. Laitakari ${ }^{1,3} \cdot$ J. K. Mäkelä-Kaikkonen ${ }^{1,3} \cdot$ E. Pääkkö ${ }^{2} \cdot$ P. Ohtonen ${ }^{1,3} \cdot$ T. T. Rautio ${ }^{1,3}$
}

Received: 3 April 2019 / Accepted: 20 June 2019 / Published online: 3 July 2019

(c) The Author(s) 2019

\begin{abstract}
Background Magnetic resonance imaging (MRI) provides excellent information about pelvic anatomy after ventral rectopexy, but the position of the conventional mesh is not seen constantly. Iron oxide-impregnated polyvinylidene fluoride (PVDF) meshes are proven to have MRI visibility in hernia or vaginal reconstructive surgery. This prospective pilot study was designed to assess the visualization, position, and shape of the magnetic resonance (MR)-visible synthetic pelvic mesh used in minimally invasive ventral rectopexy.

Methods Eight patients with pelvic organ prolapse were recruited for laparoscopic (LVMR) or robotic-assisted ventral mesh rectopexy (RVMR) with a synthetic MR-visible PVDF mesh. A follow-up visit was scheduled at 3 months after surgery. MR imaging was performed to evaluate the position and dimensions of the mesh and anatomical result. The visibility of the mesh in each sequence was assessed subjectively.

Results The visibility of the mesh was best on T1-weighted flash images. The mesh was also well visualized on T2-weighted sagittal images. T2-weighted images, in general, provided best visualization of the surrounding anatomical structures and enabled assessment of the mesh fixation.

Conclusions T2 sagittal and T1-weighted flash images provide the best information about the position and integrity of the iron oxide-impregnated PVDF mesh after LVMR or RVMR with a short examination time.
\end{abstract}

Keywords Rectal prolapse $\cdot$ Ventral rectopexy $\cdot$ Mesh $\cdot$ Magnetic resonance imaging $($ MRI) $\cdot$ MR contrasting implant $\cdot$ Iron oxide-impregnated polyvinylidene fluoride

\section{Introduction}

Laparoscopic ventral mesh rectopexy (LVMR) introduced by Andre D'Hoore has become commonly used treatment for rectal prolapse [1-4]. This minimally invasive procedure, also feasible with a robotic approach [5], offers the advantages of decreased risk of damaging autonomic nerves, recurrence, and new-onset post-operative symptoms. Anatomical and functional changes in the pelvic floor after anterior rectopexy have been described [6-8], but there are no

K. E. Laitakari

kirsi.laitakari@fimnet.fi

1 Division of Gastroenterology, Department of Surgery, University Hospital of Oulu, Oulu, Finland

2 Department of Radiology, University Hospital of Oulu, Oulu, Finland

3 Medical Research Center Oulu, University of Oulu, Oulu, Finland studies that have investigated the position and dimensions of the mesh.

The risk of mesh-related complications like erosions, mesh infection, dyspareunia or fistula formation is quite low [8-10]. However, post-operative de-novo symptoms such as urinary retention, fecal incontinence, constipation or pelvic/ abdominal pain are not so infrequent $[4,8,9,11]$. The overall recurrence rate of rectal prolapse after laparoscopic or robotic-assisted ventral mesh rectopexy (RVMR) is up to $15.4 \%$ [4-6, 8, 11]. MR-contrasting implants have been suggested to be helpful in diagnosing post-operative problems non-invasively.

The aim of this prospective pilot study was to assess the visualization, position, and dimensions of the MR-visible synthetic mesh after LVRM or RVMR. The primary outcomes were the quantificational characterization of mesh position and anatomical changes. 


\section{Materials and methods}

\section{Study population and data collection}

From February to April 2018, eight unselected consecutive patients with pelvic organ prolapse were recruited for laparoscopic or RVMR with a synthetic MR-visible polyvinylidene fluoride (PVDF) mesh in Oulu University Hospital, Finland. Written informed consent was obtained from all patients. All data about patient characteristics and post-operative recovery were collected prospectively. The study was approved by the local Ethics Committee.

\section{Surgical technique}

The surgical procedures were primarily carried out as described by D'Hoore and Penninckx [2] with minor modifications. The da Vinci Surgical System (Intuitive Surgical Inc., Sunnyvale, CA, USA) with five trocar placements and side docking was used to perform RVMR. The mesh was positioned as far distally as possible and sutured to the levator muscles and on the anterior rectal wall with multiple interrupted seromuscular non-absorbable sutures (2-0 Ethibond, Ethicon Endosurgery). In laparoscopic procedures, only four to five sutures were used to fix the mesh on the proximal rectal wall, and the distal part of the mesh was fixed with glue. For the sacral promontory fixation, spiral attachments (Pro-Tack TM Fixation Device, Medtronic) were used. The peritoneum was closed over the mesh with continuous suture with absorbable V-Loc ${ }^{\text {TM }} 90$ (Medtronic). Peri-operative care was conducted according to the enhanced recovery after surgery protocol.

\section{Mesh information}

MR-visible polyvinylidene fluoride (PVDF) $4 \times 23 \mathrm{~cm}$ meshes (Dynamesh ${ }^{\circledR}$ IPOM, FEG Textiltechnik, Aachen, Germany) containing paramagnetic iron oxide microparticles $\left(\mathrm{Fe}_{3} \mathrm{O}_{4}\right.$ with iron load of $10 \mathrm{mg} / \mathrm{g}$ polymer) were used. This macroporous ( $>1 \mathrm{~mm}$ ) mesh consists of $88 \%$ visceral-sided PDVF monofilament and $12 \%$ parietal-sided polypropylene monofilament.

\section{Follow-up}

A follow-up visit was scheduled at 3 months after surgery. Patients were evaluated for their pelvic clinical status and the functional results assessed with questionnaires reflecting quality of life and possible post-operative symptoms. MR imaging was performed for radiological evaluation of position and dimensions of the mesh and anatomical result.

\section{Magnetic resonance imaging}

Magnetic resonance imaging (MRI) was performed by a $3 \mathrm{~T}$ magnet (Siemens, Vida, Erlangen, Germany). The patients were asked to empty the bladder before imaging. No other patient preparation was used. Patients were lying supine in the magnet. A body matrix surface coil was used in addition to the posterior spine coil.

T2-weighted sagittal, coronal, and transverse images were obtained (TR 3720-6100, TE 81-90, sagittal and coronal FOV 230, transverse FOV 200, $3 \mathrm{~mm}$ slice, $0.6 \mathrm{~mm}$ gap, sagittal and coronal matrix $256 \times 320$, transverse matrix $544 \times 640)$. Breath-hold transverse $\mathrm{T} 1$-weighted vibe Dixon (TR 4, TE 1.3 and 2.5, FOV $309 \times 380,3 \mathrm{~mm}$ slice, $195 \times 320$ matrix) and T1-weighted (TR 129, TE 2.5, FOV $333 \times 380,3 \mathrm{~mm}$ slice, $210 \times 320$ matrix) flash images were also obtained. Total time of the examination was 30-35 min.

The visibility of the mesh in each sequence was assessed subjectively. Scores from 1 to 4 were used. Score 1 was given to image series if the mesh was visible in all slices. In score 2,3 , and 4 , the visibility was $\geq 3 / 4, \geq 1 / 2$ or $<1 / 2$ of the slices.

The position of the lower insertion point according to anorectal junction was assessed, as well as the insertion point to the levator muscle on each side. The length of insertion to the anterior rectal wall was measured. The width of the mesh was measured at the lower insertion point, at the highest insertion point in the rectum, and at the higher insertion point in the promontorium. Also, the narrowest part of the mesh was measured, as well as its distance from the highest rectal insertion point.

\section{Results}

Eight female patients were included in this analysis, and their baseline clinical characteristics and used surgical technique are given in Table 1 . All operations were primary except one robotic re-rectopexy for patient D (Table 1) with recurrent enterocele after previous ventral rectopexy. Mean operative time was $131 \mathrm{~min}$ (SD 44.4) and blood loss was $68 \mathrm{ml}$ (SD 138.5). One laparoscopic operation was converted to open, and patient $\mathrm{G}$ (Table 1) had mild post-operative acute myocardial infarction. There were no peri-operative or any post-operative surgical complications. Mean hospital stay was 1.5 days (SD 0.76).

All patients had a 3-month follow-up with MRI imaging. The results of mesh position and dimensions are summarized in Table 2 . The anatomical correction of the pelvic floor was excellent in all cases and there were no significant 
Table 1 Baseline characteristics and peri-operative outcome

\begin{tabular}{lllllllrr}
\hline Patient & Age (years) & ASA & BMI $\left(\mathrm{kg} / \mathrm{m}^{2}\right)$ & Diagnosis & Indication & Surgical technique & $\begin{array}{c}\text { Operation } \\
\text { time }(\mathrm{min})\end{array}$ & $\begin{array}{c}\text { Blood loss (ml) } \\
\text { A }\end{array}$ \\
\hline 63 & 3 & 24 & Enterocele & Incontinence & RVMR & 86 & 20 \\
B & 56 & 2 & 22 & Enterocele & ODS & RVMR & 90 & 400 \\
C & 88 & 3 & 22 & Prolapse & Prolapse & RVMR & 121 & 0 \\
D & 53 & 2 & 23 & Enterocele & Incontinence & RVMR $^{\mathrm{a}}$ & 174 & 0 \\
E & 77 & 3 & 27 & Prolapse & Prolapse & RVMR & 214 & 100 \\
F & 49 & 2 & 24 & Enterocele & Incontinence & LVMR & 148 & 0 \\
G & 77 & 3 & 25 & Invagination & Incontinence & LVMR & 118 & 20 \\
H & 41 & 2 & 22 & Invagination & Incontinence & LVMR & 106 & 0 \\
\hline
\end{tabular}

ASA American Society of Anesthesiologists, BMI body mass index, ODS obstructed defecation syndrome, RVMR robotic ventral rectopexy, $L V M R$ laparoscopic ventral rectopexy

${ }^{\mathrm{a}}$ Re-rectopexy

${ }^{\mathrm{b}}$ Conversion

Table 2 Pelvic floor area measurements on MRI

\begin{tabular}{|c|c|c|c|c|c|c|c|c|c|}
\hline \multirow[t]{2}{*}{ Patient } & \multicolumn{9}{|l|}{ Parameter } \\
\hline & $\begin{array}{l}\text { Anorectal } \\
\text { junction }^{\mathrm{a}}\end{array}$ & $\begin{array}{l}\text { Right levator } \\
\text { muscle }^{b}\end{array}$ & $\begin{array}{l}\text { Left levator } \\
\text { muscle }^{c}\end{array}$ & $\begin{array}{l}\text { Anterior } \\
\text { rectal wall }^{\mathrm{d}}\end{array}$ & $\begin{array}{l}\text { Lower inser- } \\
\text { tion point }{ }^{\mathrm{e}}\end{array}$ & $\begin{array}{l}\text { Highest inser- } \\
\text { tion point }{ }^{\mathrm{f}}\end{array}$ & $\begin{array}{l}\text { Narrowest } \\
\text { part }^{\mathrm{g}}\end{array}$ & $\begin{array}{l}\text { Distance from the } \\
\text { insertion point }^{\mathrm{h}}\end{array}$ & $\begin{array}{l}\text { Promon- } \\
\text { torium }^{\mathrm{i}}\end{array}$ \\
\hline A & 0 & Yes & Yes & 93 & 36 & 28 & 16 & 6 & 22 \\
\hline B & 0 & Yes & Yes & 86 & 31 & 23 & 15 & 5 & 20 \\
\hline $\mathrm{C}$ & 0 & Yes & Yes & 87 & 40 & 33 & 17 & 20 & 26 \\
\hline $\mathrm{D}$ & 0 & Yes & No & 105 & 40 & 45 & 19 & 15 & 34 \\
\hline $\mathrm{E}$ & 20 & Yes & Yes & 43 & 34 & 22 & 10 & 42 & 22 \\
\hline $\mathrm{F}$ & 0 & Yes & Yes & 79 & 45 & 29 & 28 & 14 & 26 \\
\hline G & 0 & Yes & Yes & 96 & 38 & 30 & 15 & 32 & 38 \\
\hline $\mathrm{H}$ & 7 & Yes & Yes & 58 & 43 & 29 & 11 & 26 & 33 \\
\hline
\end{tabular}

MRI magnetic resonance imaging

${ }^{a}$ Distance of the lower insertion point from the anorectal junction (mm)

${ }^{\mathrm{b}}$ The position of the insertion point to the right levator muscle

${ }^{\mathrm{c}}$ The position of the insertion point to the left levator muscle

${ }^{\mathrm{d}}$ Length of insertion to the anterior rectal wall $(\mathrm{mm})$

${ }^{\mathrm{e}}$ Width of the mesh at the lower insertion point $(\mathrm{mm})$

${ }^{\mathrm{f}}$ Width of the mesh at the highest insertion point in the rectum (mm)

${ }^{\mathrm{g}}$ Narrowest part of the mesh ( $\left.\mathrm{mm}\right)$

${ }^{\mathrm{h}}$ The distance of the narrowest part of the mesh from the highest rectal insertion point (mm)

${ }^{\mathrm{i}}$ Width of the mesh at the higher insertion point in the promontorium ( $\mathrm{mm}$ )

differences in any proportions of the meshes. Fixation of the meshes to the levator muscles and to promontorium was also seen (Fig. 1b; Table 2).

The visibility of the mesh was best on T1-weighted flash images (scoring 1 in all cases) as shown in Table 3. The mesh was also well visualized on T2-weighted sagittal images (scoring 1 in six cases, 3 in one case, and 4 in one case with severe movement artifacts). T2-weighted images, in general, provided best visualization of the surrounding anatomical structures (Fig. 1).

\section{Discussion}

This pilot study was designed to find the best way to visualize the iron oxide-impregnated PVDF meshes implanted for rectal prolapse. Our results showed that position and dimensions of this new mesh are seen sufficiently to make measuring using post-operative MRI. This would be useful in cases of post-operative mesh-related complications and recurrent symptoms; particularly, when planning 

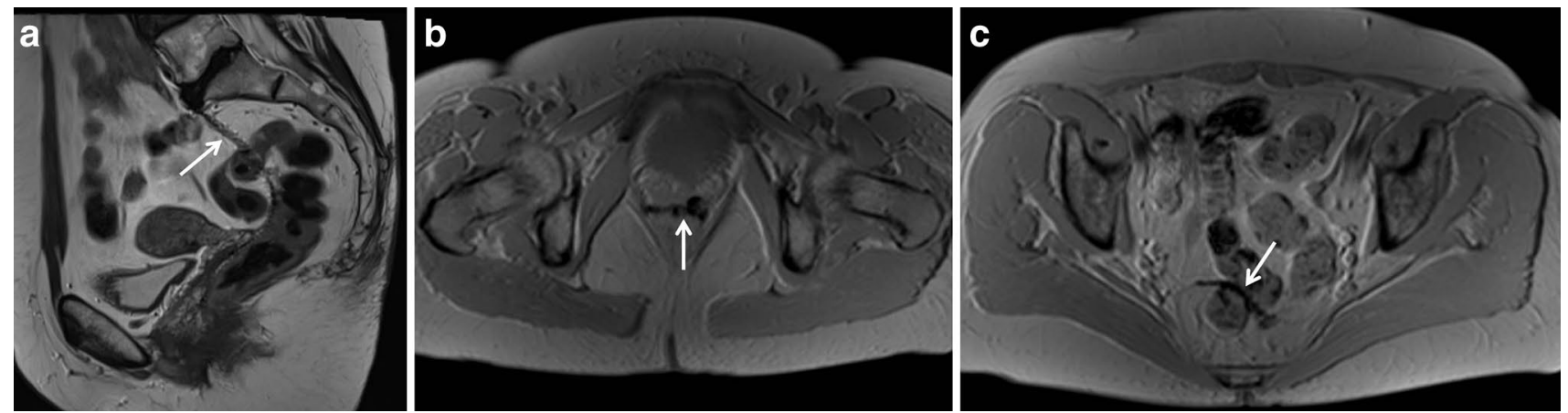

Fig. 1 a The mesh is visualized in its full length on T2-weighted sagittal image. On T1-weighted flash images, the mesh is also well visualized close to the lower insertion point (b) and at the higher insertion on the rectal wall (c)

Table 3 The visibility of the mesh in MRI sequences

\begin{tabular}{lllllll}
\hline Patient & \multicolumn{2}{l}{ MRI sequence } & & & \\
\cline { 2 - 7 } & T2 sagittal & T2 transverse & T2 coronal & T1 flash & $\begin{array}{l}\text { Dixon in } \\
\text { phase }\end{array}$ & $\begin{array}{l}\text { Dixon out } \\
\text { of phase }\end{array}$ \\
\hline A & 1 & 4 & 4 & 1 & 2 & 4 \\
B & 3 & 4 & 4 & 1 & 2 & 4 \\
C & 1 & 3 & 4 & 1 & 1 & 4 \\
D & 4 & 4 & 4 & 1 & 2 & 4 \\
E & 1 & 3 & 3 & 1 & 1 & 4 \\
F & 1 & 4 & 4 & 1 & 2 & 4 \\
G & 1 & 2 & 3 & 1 & 2 & 4 \\
H & 1 & 3 & 3 & 1 & 2 & 4 \\
\hline
\end{tabular}

1 , mesh was visible in all slices; 2 , visibility was $\geq 3 / 4$ of the slices; 3 , visibility was $\geq 1 / 2$ of the slices; 4 , visibility was $<1 / 2$ of the slices

MRI magnetic resonance imaging reoperation to check if the mesh has gotten detached from the pelvic floor or promontory attachments.

There are few previous results showing the feasibility of iron oxide-impregnated PVDF meshes in hernia and vaginal reconstructive surgery [12-15]. However, this is the first study to demonstrate how the MR-visible synthetic mesh is seen after LVMR or RVMR in post-operative MRI. Therefore, it is impossible to compare our results to any previous data. We hope that other study groups will get interested in doing further research on iron oxideimpregnated PVDF meshes.

If the position and integrity of the mesh are in question, $\mathrm{T} 2$ sagittal and T1-weighted flash images would provide sufficient information with a short examination time. However, if there are other post-operative concerns, such as infection, a wider selection of sequences should be used together with intravenous contrast agent. Acquired information helps the design of future studies comparing different ventral rectopexy techniques, and especially mesh fixation alternatives.

\section{Conclusions}

T2 sagittal and T1-weighted flash images provide the best information about the position and integrity of the iron oxideimpregnated PVDF mesh after LVMR or RVMR with a short examination time.

Acknowledgements Open access funding provided by University of Oulu including Oulu University Hospital.

Author contributions KL: acquisition, analysis and interpretation of data, writing the article. JKM: conception and design of the study, acquisition, analysis and interpretation of data. EP: design of the study, analysis and interpretation of data, writing the article, critical revision. PO: design of the study, analysis and interpretation of data, writing the article, critical revision. TTR: conception and design of the study, acquisition, analysis and interpretation of data, writing the article.

Funding State research funding. 


\section{Compliance with ethical standards}

Conflict of interest The authors declare that they have no conflict of interest.

Ethical approval The study has been approved by the Ethical Committtee of the Oulu University Hospital.

Informed consent Written informed consent was obtained from all patients.

Open Access This article is distributed under the terms of the Creative Commons Attribution 4.0 International License (http://creativeco mmons.org/licenses/by/4.0/), which permits unrestricted use, distribution, and reproduction in any medium, provided you give appropriate credit to the original author(s) and the source, provide a link to the Creative Commons license, and indicate if changes were made.

\section{References}

1. D'Hoore A, Cadoni R, Penninckx F (2004) Long-term outcome of laparoscopic ventral rectopexy for total rectal prolapse. Br J Surg 91:1500-1505

2. D'Hoore A, Penninckx F (2006) Laparoscopic ventral recto(colpo) pexy for rectal prolapse: surgical technique and outcome for 109 patients. Surg Endosc 20:1919-1923

3. Faucheron JL, Trilling B, Girard E, Sage PY, Barbois S, Reche F (2015) Anterior rectopexy for full-thickness rectal prolapse. Technical and functional results. World J Gastroenterol 21:5049-5055

4. Van Iersel JJ, Paulides TJ, Verheijen PM, Lumley JW, Broeders IA, Consten EC (2016) Current status of laparoscopic and robotic ventral mesh rectopexy for external and internal rectal prolapse. World J Gastroenterol 22:4977-4987

5. Van Iersel JJ, Formijne Jonkers HA, Paulides TJC, Verheijen PM, Draaisma WA, Consten ECJ, Broeders IAMJ (2017) Robot-assisted ventral mesh rectopexy for rectal prolapse: a 5 -year experience at a tertiary referral center. Dis Colon Rectum 60:1215-1223

6. Mäkelä-Kaikkonen J, Rautio T, Kairaluoma M, Carpelan-Holmström M, Kössi J, Rautio A, Ohtonen P, Mäkelä J (2018) Does ventral rectopexy improve pelvic floor function in the long term? Dis Colon Rectum 61:230-238
7. Tsunoda A, Takahashi T, Hayashi K, Yagi Y, Kusanagi H (2018) Laparoscopic ventral rectopexy in patients with fecal incontinence associated with rectoanal intussusception: prospective evaluation of clinical, physiological and morphological changes. Tech Coloproctol 22:425-431

8. Consten EC, van Iersel JJ, Verheijen PM, Broeders IA, Wolthuis AM, D'Hoore A (2015) Long-term outcome after laparoscopic ventral mesh rectopexy: an observational study of 919 consecutive patients. Ann Surg 262:742-747

9. Evans C, Stevenson AR, Sileri P, Mercer-Jones MA, Dixon AR, Cunningham C, Jones OM, Lindsey I (2015) A multicenter collaboration to assess the safety of laparoscopic ventral rectopexy. Dis Colon Rectum 58:799-807

10. Smart NJ, Pathak S, Boorman P, Daniels IR (2013) Synthetic or biological mesh use in laparoscopic ventral mesh rectopexy-a systematic review. Colorectal Dis 15:650-654

11. McLean R, Kipling M, Musgrave E, Mercer-Jones M (2018) Short- and long-term clinical and patient-reported outcomes following laparoscopic ventral mesh rectopexy using biological mesh for pelvic organ prolapse: a prospective cohort study of 224 consecutive patients. Colorectal Dis 20:424-436

12. Sindhwani N, Callewaert G, Deprest T, Housmans S, Van Beckevoort D, Deprest J (2018) Short term post-operative morphing of sacrocolpopexy mesh measured by magnetic resonance imaging. J Mech Behav Biomed Mater 80:269-276

13. Chen L, Lenz F, Alt CD, Sohn C, De Lancey JO, Brocker KA (2017) MRI visible $\mathrm{Fe}_{3} \mathrm{O}_{4}$ polypropylene mesh: 3D reconstruction of spatial relation to bony pelvis and neurovascular structures. Int Urogynecol J 28:1131-1138

14. Joukhadar R, Meyberg-Solomayer G, Hamza A, Radosa J, Bader W, Barski D, Ismaeel F, Schneider G, Solomayer E, Baum S (2015) A novel operative procedure for pelvic organ prolapse utilizing a MRI-visible mesh implant: safety and outcome of modified laparoscopic bilateral sacropexy. Biomed Res Int 2015:860784

15. Muysoms F, Beckers R, Kyle-Leinhase I (2018) Prospective cohort study on mesh shrinkage measured with MRI after laparoscopic ventral hernia repair with an intraperitoneal iron oxideloaded PVDF mesh. Surg Endosc 32:2822-2830

Publisher's Note Springer Nature remains neutral with regard to jurisdictional claims in published maps and institutional affiliations. 